TEXTOS Y DOCUMENTOS 



\title{
Carlos Fuentes, Homero Garza y el número de aniversario de Kátharsis
}

\author{
Rodrigo Garza Arreola \\ rodrigo@uchicago.edu
}

\begin{abstract}
Resumen: Se presenta y analiza una carta inédita de Carlos Fuentes dirigida a los editores de la revista Kátharsis, en 1956. Para situarla, se presentan aspectos de la obra de uno de los destinatarios de la carta, Homero Garza, que dan testimonio de la generosidad de Fuentes para colaborar con proyectos de jóvenes creadores. Además se comentan las colaboraciones de Alfonso Reyes, Octavio Paz, Carlos Fuentes y Amparo Dávila, para el número de aniversario de Kátharsis y se sugiere que existe un hilo conductor entre ellas, en torno al concepto de catarsis.
\end{abstract}

AвSTRACT: This article presents and analyzes an unpublished letter written by Carlos Fuentes in 1956 to the editors of the literary magazine Kátharsis. To offer background, it portrays some features of the work of one of the recipients of the letter, Homero Garza, that attest to Fuentes' generosity to collaborate with the projects of young writers. In addition, the article includes a commentary on the original works contributed by Alfonso Reyes, Octavio Paz, Amparo Dávila and Fuentes himself to the anniversary issue of Kátharsis and suggests that between them, there is a common thread revolving around the concept of catharsis.

Palabras clave: Carlos Fuentes, Kátharsis, Homero Garza, Alfonso Reyes, Octavio Paz.

Keywords: Fuentes, Kátharsis, Homero Garza, Alfonso Reyes, Octavio Paz.

Se presenta una carta de Carlos Fuentes fechada el 8 de septiembre de 1956, enviada desde la ciudad de México a Monterrey, a dos de los fundadores de la revista literaria Kátharsis, ${ }^{1}$ Hugo Padilla y Homero Garza; la carta se encontró entre los libros y papeles de este último, por lo que

${ }^{1}$ El gobierno de Nuevo León editó, en versión facsímil, todos los números de esta revista literaria que apareció de manera irregular entre 1955 y 1960, ver Kátharsis 1994. 
los elementos para situarla y darle contexto se basan, principalmente, en ciertos datos sobre él y su obra.

En el saludo, Fuentes llama a estos jóvenes regiomontanos "Ilustres colegas". En esa época, el autor de Los días enmascarados dirigía la Revista Mexicana de Literatura, junto a Emmanuel Carballo; en su número 6, titulado Nuevos Escritores Mexicanos, correspondiente a julio-agosto de 1956, se habían incluido textos de los dos destinatarios de la carta, a lado de otros diez autores.

El objetivo de la misiva es remitir la "prometida colaboración"; se trata de un texto en forma de diálogo escénico titulado Sumar, restar, que aparecería en el número del primer aniversario de la revista $K a ́$ tharsis, el cual reuniría textos de jóvenes creadores regiomontanos con trabajos inéditos de autores del ámbito nacional, que en ese momento ya contaban con una obra publicada y reconocida. Hasta donde se ha podido investigar, Fuentes no recopiló esta colaboración en alguno de sus libros posteriores.

En el cuerpo de la carta, Carlos Fuentes muestra, además de humor e ingenio, generosidad para compartir experiencias, ideas y relaciones personales. El escrito combina expresiones coloquiales con comentarios cultos; menciona, por ejemplo, un conocimiento compartido que incluye las jitanjáforas —en alusión al maestro común, Alfonso Reyesasí como referencias a Carlos Pellicer, Octavio Paz y José Gorostiza.

En la despedida, el autor les desea suerte, a ellos y a su revista, y señala que espera verlos el año siguiente (1957), masticando el polvo de la región más trasparente del aire; de nuevo una alusión a Reyes y, por otra parte, una referencia a la gran novela que por esos días seguramente preparaba.

Los buenos deseos de Carlos Fuentes se materializaron; unas semanas después, los destinatarios de la carta recibirían un comunicado de Alfonso Reyes, ${ }^{2}$ fechado el 21 de noviembre de 1956, mediante el cual, en su calidad de presidente de El Colegio de México, les informa que dicha institución les otorgaría una suma mensual por todo el año de 1957, como ayuda para sus estudios en la Facultad de Filosofía y Letras de México.

\footnotetext{
${ }^{2}$ El comunicado de Reyes también se encontró entre los documentos de Homero Garza.
} 
Huberto Batis ofrece una referencia a la llegada de estos jóvenes escritores a la ciudad de México, en su libro Lo que Cuadernos del Viento nos Dejó:

Recuerdo un mediodía allá por 1957 en la calle de Orizaba, en un café donde nos tuvieron azorados con sus chismes literarios Manuel Calvillo, el secretario de don Alfonso Reyes y Alí Chumacero, siempre en el Fondo de Cultura, a los nuevos becarios de Guadalajara y Monterrey: Emmanuel Carballo, Carlos Valdés y yo, Hugo Padilla, Arturo Cantú y Homero Garza. Los tres últimos habían llegado con su revista Kátharsis, bella y estricta (20).

Durante ese año, Padilla y Garza sustituirían a Fuentes y Carballo como responsables en algunos números de la Revista Mexicana de Literatura. También en 1957, en un escrito del 19 de diciembre, Octavio Paz se refiere a Kátharsis como "la revista de los muchachos de Monterrey", en una carta dirigida a Gabriel Zaid, quien la incluyó al inicio de la primera edición de su poemario Seguimiento (Carta-Prólogo).

\section{II}

En 1967, en una entrevista para un periódico de Monterrey, Homero Garza relata que Hugo Padilla, Arturo Cantú y él fundaron la revista Kátharsis; ${ }^{3}$ añade que posteriormente se agregaron colaboradores como Carmen Alardín, Ramiro Garza, Raymundo Ramos Gómez, Alfonso Rangel Guerra, Rafael Estevez, Enriqueta Ochoa y otros que vinieron después (Marthel: 10-11).

En la entrevista Garza comenta que esta publicación no oficial de provincia fue la primera revista literaria de jóvenes de Monterrey; su aparición fue bien recibida en la capital y, como su distribución alcanzaba España y Argentina, de estos países recibieron cartas y colaboraciones.

Homero Garza señala que para el número de aniversario recibieron de la ciudad de México, además de la de Carlos Fuentes, colaboraciones

\footnotetext{
${ }^{3}$ Según recuerda Hugo Padilla en una conferencia de 1983, el nombre Kátharsis lo sugirió al grupo Homero Garza, quien estudiaba medicina y lo había tomado de Sigmund Freud (Kátharsis: 12-13).
} 
inéditas de Alfonso Reyes, Octavio Paz y Amparo Dávila, lo que sirvió para consolidar el prestigio de la revista. ${ }^{4}$ Eligio Coronado, estudioso de la poesía de Nuevo León, indica que fue la revista Kátharsis la que introdujo la vanguardia literaria en Monterrey (24). Respecto a los poemas de Homero Garza apunta: "son estructuras verbales donde la intensidad creadora escudriña las posibilidades de la metáfora. La temática varía entre el amor y la exploración del ser y es de naturaleza pretextual: su función es propiciar el ejercicio poético y estimular la libre asociación imaginativa la cual, a su vez, se sustenta en el amplio registro sensorial del autor" (285).

Para ofrecer una idea del carácter de la revista, se analizan los textos que publicó Homero Garza en esa época. En su poesía la brisa tiene arterias, el agua, células, la voz se alimenta de fantasmas, el alma posee corteza, el llanto, piel, el letargo eleva espigas, las palabras tienen dientes de astillas y devoran todo, la astilla y el polvo lloran, el paisaje tiene alas que se abren en los ojos, la lluvia tiene labios transparentes. Lo anterior se refleja en su poema incluido en el número de aniversario titulado Más allá de las cosas azules y bárbaras, en donde "El amor entra cantando con astillas de barcos en los labios, / y mástiles que lloran su derribada estirpe" (Kátharsis: 112).

Estas imágenes, donde lo inanimado se vuelve orgánico, ponen en movimiento signos y significados, una dialéctica entre la superficie y lo profundo, expresada en los contrastes del silencio y el grito, el deseo y la realidad, la noche y el día o la vida y la muerte. Sin embargo, no son los contrastes lo que más le interesa explorar con sus imágenes poéticas, su interés radica en el límite, donde dos esencias se impactan y se confunden, se procrean o transforman, es decir en la catarsis. En sus versos encontramos con frecuencia referencias a este límite, que adquiere formas de litoral, corteza, borde, o bien, aspectos más orgánicos y eróticos, de piel, ósculo, contacto o fricción.

En 1984, en la revista Estaciones de Monterrey, Homero Garza publica un poema titulado El Eterno Retorno, en el que evoca su experien-

\footnotetext{
${ }^{4}$ Homero Garza menciona que la revista posteriormente contó con las colaboraciones de José de la Colina, Antonio Montaña, Fernando Sánchez Mainez, Abigail Bogórquez y jóvenes regiomontanos como Ario Garza Mercado, Samuel Flores Longoria, José Ángel Rendón, Jorge Cantú de la Garza, Salomón González Almazán, Ernesto Rangel Guerra, Gabriel Zaid e Isabel Freire (Marthel: 10-11).
} 
cia como becario de El Colegio de México. La exuberancia de imágenes de su poesía de juventud da el paso a la introspección y a la ironía:

En 1957 me sentía en el aire de la región más transparente, sin raíces volando, deshabitado, lo mismo que un fantasma.

México era un bello paraíso inhóspito, Monterrey un edén infernal idealizado.

Entre el infierno perdido y el paraíso no deseado, estaba mi derrumbe interior ensimismado en el nirvana del exilio nostálgico.

Nunca el calor canicular de Monterrey ha sido por tanto amor correspondido

(Garza: 41).

En su poesía posterior persiste la exploración de los contrastes y sus límites, que dan lugar a reflexiones sobre la esencia y la existencia, lo fugaz y lo eterno, lo estático y lo dinámico, la presencia y la ausencia; pero ahora el énfasis en el movimiento catártico, en busca de la libertad del alma, dentro del laberinto del amor y del lenguaje, se ve influido por su experiencia y autoexamen como psiquiatra y psicoanalista.

Con la influencia de la práctica clínica, sus poemas que aparecieron esporádicamente en suplementos culturales, tienen títulos como Proceso Primario, Ambivalencia o Vicisitudes del Deseo. El caso de Homero Garza parece ajustarse a la reflexión que hiciera Huberto Batis: "mi generación llegó a los hospitales, a los manicomios, a las cátedras de las universidades y a los suplementos culturales" (2001: 272).

\section{III}

En contraste con los críticos que acusaron a Reyes de falta de nacionalismo por su afición a Grecia, los fundadores de Kátharsis eligen un término de origen helénico para su revista y su grupo. En este sentido, se sugiere que los textos incluidos en el número del primer aniversario 
de la revista, tanto de autores del ámbito nacional como de los jóvenes regiomontanos, participan de cierta manera de una visión común en torno al concepto de catarsis, sintetizando y articulando elementos que en ese momento se encontraban en el ambiente literario, en un México que abría, generoso, sus puertas al mundo.

El número de aniversario de Kátharsis abre con la colaboración de Alfonso Reyes, se trata de "Etapas de la creación", que fue recopilado en su libro Al Yunque, el cual recoge ensayos en los que el autor retoma temas expuestos en El deslinde, pero tratados de manera menos formal. El texto de Reyes habla explícitamente "de los alivios de la Kátharsis" como una de las etapas de la creación; en este caso, a diferencia de lo que señala Aristóteles en su Poética, la catarsis opera en el autor del texto literario, no en el lector o espectador. Ciertamente, las jitanjáforas y la Región más Transparente del Aire, son términos vinculados a Reyes, como también lo es, quizá de manera más discreta, la catarsis o purificación a través de la poesía. Octavio Paz señala que "Reyes escribió una y otra vez que la tragedia es la forma más alta y perfecta de la poesía porque en ella la desmesura encuentra al fin su tensa medida y, así, se purifica y redime" (227-228). En este sentido, parecería que, a diferencia de lo que sugiere Ernesto Mejía Sánchez, ${ }^{5}$ la simpatía de Reyes por los jóvenes fundadores de Kátharsis, podría haber partido de algo más profundo que el simple hecho de ser regiomontanos.

Por su parte, la colaboración de Octavio Paz, "Cabeza de ángel”, que fue recopilado en la sección Arenas movedizas de su libro de narraciones y poemas en prosa ¿Águila o sol? es un texto escrito como flujo de conciencia, en un ambiente entre el sueño y la vigilia, enfatizado por la ausencia casi total de signos de puntuación. En el caso de Amparo Dávila, su colaboración se titula "Un boleto para cualquier parte", reunido en su libro Tiempo destrozado; en este caso, Dávila utiliza el flujo de conciencia para describir el estado mental del personaje, que sufre delirios de persecución. Curiosamente, tanto la voz femenina del texto de Paz como la voz masculina de Dávila, en su respectiva corriente de pensamiento, señalan el deseo, velado o explícito, de la muerte de la

\footnotetext{
${ }^{5}$ En el Estudio preliminar al tomo XXI de las Obras completas de Alfonso Reyes, Ernesto Mejía Sánchez apunta: “"Etapas de la creación” (1947) apareció en Kátharsis, de Monterrey, Nuevo León, agosto-septiembre de 1956, núms. 12-13, pp. 2-8, con facsímil de la firma de Reyes al fin; esta revista gozó de la simpatía de Reyes, quizá por ser sus paisanos los jóvenes poetas que la fundaron" (2000: XXXIV).
} 
madre, lo cual pareciera tener resonancias de drama griego, o de subconsciente colectivo.

En Sumar, restar, Carlos Fuentes efectivamente colabora con Kátharsis; elige, con cierta ironía, el diálogo escénico, la forma clásica señalada por Aristóteles para la catarsis; pone en acción a tres personajes, un griego (Pitágoras), a una forma pura (el número uno) y a un mexicano (un vendedor de lotería de la ciudad de México). De forma casual, tanto el texto de Fuentes como el de Paz utilizan la decapitación como elemento catártico dentro de su colaboración. Además de estos elementos, el texto de Fuentes se desarrolla en un ambiente onírico y hace uso de la libre asociación, tanto de ideas como de sonidos, creando algunas jintanjáforas, para utilizar el término previamente referido, jugando con frases del oráculo de Delfos, de Shakespeare o de Quevedo, en otros:

Dikes trópulos, dikes diké

En una playa me pregunté

Vous savez ça la doute est la foi,

Tu la tu la tula tuá

Ergo cogito ergo sum

Dikes trópulos dike diké

Gnothi seauton Socraté

Dikes trópulos dike diké

To die to sleep perchance to dream

Sin la pensión de procurar mi muerte

Dikes trópulos Dikes Diké

(Kátharsis: 115).

Carlos Fuentes utilizaría el flujo de conciencia, con rasgos de libre asociación de ideas, en sus momentos más líricos, a lo largo de sus obras, desde los monólogos de la ciudad de México en La región más transparente, pasando por los tres pronombres y los tres tiempos verbales que confluyen en la conciencia de Artemio Cruz, hasta los soliloquios de Cristóbal nonato, desde el vientre de su madre, o la cabeza decapitada de La voluntad o la fortuna, por mencionar solo algunos ejemplos entre su vasta narrativa. Desde luego Fuentes utilizó la forma de diálogos escénicos en obras de teatro, guiones para cine, e incluso un libreto para ópera; las características de flujo de conciencia y catarsis destacan en el drama de la conquista, Todos los gatos son pardos. 
La carta de Carlos Fuentes y la publicación a la que fue dirigida, representan testimonios de auténtica colaboración entre autores de distintas generaciones y de diferentes ámbitos. Un esfuerzo colectivo y espontáneo en torno a la literatura que permite evocar las palabras de Alfonso Reyes al final de su libro El deslinde:

Aquí llegados, nos detenemos, pues, a las puertas de la poesía. Catharsis para el ánimo, edificación en la ética, vivificación en la política, compensación para los vacíos del mundo, enriquecimiento de la especie, camino de la humanización del hombre, guía en tormenta, brecha en ahogo —ella liberta, ella levanta: no sin henchir antes de arrullos, a imagen de la canción de Ariel, las pausas de la noche de Fausto (1997: 421-422).

\section{Bibliografía}

Batis, Huberto. Lo que Cuadernos del Viento nos Dejó, México: Consejo Nacional para la Cultura y las Artes, 1994 (Lecturas Mexicanas, Tercera Serie, 71).

Batis, Huberto. Por sus comas los conoceréis. México: Consejo Nacional para la Cultura y las Artes, 2001 (Colección Periodismo Cultura).

Coronado, Eugrio. Antología de la poesía Nuevoleonesa. Monterrey: La Biblioteca de Nuevo León, 1993.

Garza, Homero. "Poemas", en Estaciones, volumen 1, número 1. Monterrey, Nuevo León, verano 1984.

KáthaRsIs. 1955-1960. Edición facsimilar. Texto preliminar de Hugo Padilla. Monterrey: Gobierno del Estado de Nuevo León, 1994.

Marthel, Hermila. "Aquella Dorada Edad de Kátharsis", en El Porvenir, Monterrey, Nuevo León, 12 de noviembre de 1967.

Paz, Octavio. "El jinete del aire: Alfonso Reyes", en Obras Completas 4. México: Fondo de Cultura Económica, tercera reimpresión, 2003.

Reyes Alfonso. Obras completas de Alfonso Reyes, tomo XV, México: Fondo de Cultura Económica, segunda reimpresión, 1997.

Reyes Alfonso. Obras completas de Alfonso Reyes, tomo XXI, México: Fondo de Cultura Económica, segunda reimpresión, 2000.

Zaid, Gabriel. Seguimiento. México: Fondo de Cultura Económica, primera edición, 1964. 


\section{REVISTA MEXICANA DE LITERATURA RESPONSAGLES: CARLOS FUENTES Y EMMANUEL CARBALLO}

GERENTE:

EMILID DBREGQN

AV, JUAREZ 30

MEXICD 1, D. F.

X6xice, D.F., 8 ie septi enbre de 1956

3res. Hugo Padilla y Homero A. Garza Responeabl ea do la Revista "Katharsis" Aportado 1625

Monterr $\approx, \mathbb{N}$. L.

\section{Ilustres colegest}

Aquí va la prometíla colaberación. 81 de a tiro les parece pinche (verán que

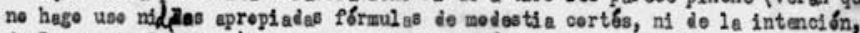
de Røyes sic Pellicer). denasiado large, avísema para enviarles algo más corto.

Les rugge que po acusen reolbo: en Néxico también los aviones pertioipen de $1_{2}$

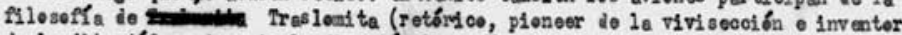
de la fitanfáfora iurante Is innatía Shonegón, descubs erto por Ootavio $\mathrm{Paz}$ en un burdel li tueno de Toldo).

TPual eron ver al poete Gerestiza?supenge que eso "ninute inoendescente" do todas las maduraciones (como pose, no tiene rivali practíquenla) el fumerario Reves Ruiz, interceptó el passaje del Gran Jefe Sitiado-Dh-Su-Byilennis.

Nucho Exi to les deseo, a ustedes $\mathrm{y}$ a "Katharsis", los esperanes el afio entrante a mesticar el polvo de le regín más trengperento del afre.

Abrazos ool eotives,

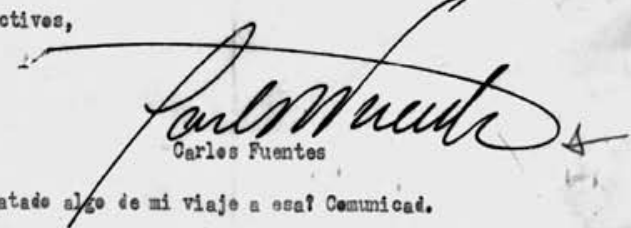
Bo ans $\rightleftharpoons$

P.S. : than tratado a. 50 de mi viajo a osa? Coumicad. 